\title{
Doctors v. government: taking the fight online
}

\section{Part III: Ontario Medical \\ Association makes savvy use of social media to protest cuts to medical fees}

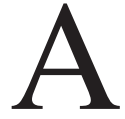

nyone with a smartphone and thumbs can use social media.

But using it to rally support for a cause, and doing it well, is a different matter. The Twitterverse is a noisy place. Getting attention on the Internet can prove challenging because - hey, check out this picture of a weasel riding a woodpecker!

Still, despite the chaos online, a wellrun social media campaign can pay off. Politicians have known this for some time, including the Hawaii-born basketball junkie who won the last two US presidential elections (@BarackObama). Could it also work for Canadian physicians protesting cuts to their fees?

On Jan. 15, a social media campaign centred on the hashtag \#CareNotCuts was launched by the Ontario Medical Association (OMA), which represents the province's 28000 doctors in fee negotiations with the government. Those negotiations had just broken down, and then the province announced it was cutting all fees for medical services by $2.65 \%$.

Now, nearly two months later, the \#CareNotCuts campaign is still going strong. So, how is the OMA faring in its initial foray into hashtag politicking? Not too shabby, it turns out.

"They have a very savvy strategy," said Aimée Morrison (@digiwonk), an associate professor of English at the University of Waterloo who studies social media, digital humanities and new media design.

The smartest thing the OMA is doing, on both Twitter and Facebook, is focusing on sharing content rather than just flooding its online channels with its own talking points, said Morrison. Though some of the posts originate from the OMA, most are curated from other sources: links to favourable media coverage, retweets of doctors concerned

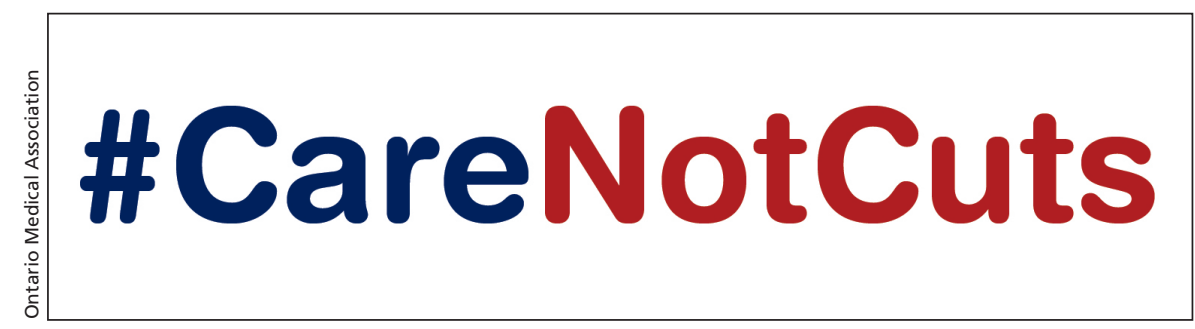

Tweets with this hashtag have reached more than $\mathbf{2 . 4}$ million Twitter accounts, according to the OMA.

about the impact of fee cuts on wait times, videos of medical students worried about the future of health care.

An organization that can use other people to get its message across not only avoids all the heavy lifting, it also skirts the risk of looking like a bleating, online blowhard. "It looks like they are performing a service on behalf of all these people who are disgruntled about what's going on," said Morrison. "They also look like they are being very humble and stepping out of the way to let others speak."

Even the association's Twitter handle — @ OntariosDoctors — creates a positive vibe. "It sounds like a friendly collection of people who give you your flu shot," said Morrison. "It doesn't sound like a lobbying organization."

The OMA is also doing a good job of framing the narrative, said Morrison. It is using phrases like "cuts to health care funding" and "cuts to patient care" instead of talking about reduced physician compensation. The story thus becomes government hurting patients rather than doctors seeking more money.

Though this tactic is more likely to gain public support, it can go too far, warned Morrison. The OMA might alienate Ontarians if its fight with the government appears in any way to threaten the much-adored public health care system or open the door for private medicine.

"If you demonize the government to the extent that people don't think it is qualified to administer health care, you are at risk of demolishing your single- payer system," said Morrison. "This is a fine line."

Another thing the OMA should be wary of is asking members of the public to take action before they are fully engaged in the campaign, said Clay Schossow (@newmediaclay), one of the founders of New Media Campaigns, a web design and marketing agency in Carrboro, North Carolina. Right at the top of the OMA campaign website, the reader is implored to "contact your MPP" and is provided a template for a letter.

"To go from visiting a website straight to taking action, that's a big jump," said Schossow.

Social media campaigns tend to be more successful when people are given the tools to "work up the ladder of engagement," he said. Small actions lead to big actions. It might be more effective, for example, to have website visitors sign up for an email newsletter before asking them to write their MPPs.

Overall, though, the OMA is using the web pretty effectively, said Schossow. Like Morrison, he praised the Twitter strategy of retweeting positive messages to give OMA supporters the loudest voice. And the campaign website does a good job of integrating all of OMA's messaging in one place. It promotes the \#CareNotCuts hashtag, pulls in its latest tweets and links to campaign ads and all its social media platforms.

"Combining these efforts together will ultimately yield more success than if each stood on its own with no central theme or hub," Schossow wrote in an email. 
From the OMA's perspective, the \#CareNotCuts social media campaign has already been a success. The reaction online has been incredibly positive, with the public, physicians and other health care providers all engaging in the discussion, according to OMA President Ved Tandan (@VedTandan).

"We are happy to see that many physicians have been inspired to carry the conversation onto other online mediums, such as blogs, to express their concerns and educate the public on the impacts that these cuts will have on patient care," Tandan stated in an email.

As of Mar. 2, the hashtag \#CareNotCuts had been used more than 7500 times and tweets including the hashtag had reached more than 2.4 million Twitter accounts, according to the OMA. During the same period, engage- ment on OMA's Facebook page increased by around $300 \%$ and posts related to the campaign were shared more than 3000 times.

"We've learned that social media is a valuable tool for advocacy and we've had great success in connecting with online communities who are able to amplify our message and share information more widely," Tandan stated in the email. "While a social media campaign may not change the government's decisions, the \#CareNotCuts campaign gives physicians and patients an online platform to voice their concerns, give feedback and suggestions, and participate in discussions with people they may never have the opportunity to meet in real life." — Roger Collier, CMAJ

CMAJ 2015. DOI:10.1503/cmaj.109-5015

\section{No more "internes": CAIR rebrands}

$\mathrm{I}$ nternes? Most Canadians don't spell it with the second "e," but that wasn't all that was outdated about the moniker Canadian Association of Internes and Residents (CAIR).

Internships ended in Canada more than two decades ago, and CAIR has apparently been discussing a name change for almost as long. Now it's actually happened. After consulting with board members, stakeholders and residents, CAIR has a new name: Resident Doctors of Canada.

The term "interne" is a vestige of how the medical education system used to work, says Laura Spragge, the group's communications manager. Canadian medical school graduates used to serve one-year internships to obtain general licences to practise medicine and could then opt to pursue specialty training. But that ended in 1993.

"This year was a particularly good opportunity for rebranding because we also underwent many other transformations," says Dr. Christina Nowik, the association's president.

These changes include a governance review and a new strategic plan to focus on training (including curriculum development, accreditation and

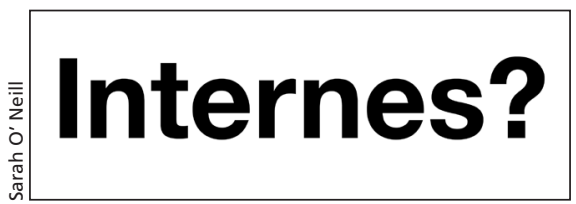

There haven't been medical "internes" in Canada in decades.

examination policy), wellness (to help residents become "healthy and resilient doctors") and representation (as the "unified voice" of Canada's 9000 residents).

It was time to make CAIR "a more modern and streamlined organization," says Nowik. Feedback on the changes has been positive so far, although she acknowledges that there is always confusion accompanying a name change. "CAIR was a nice acronym, I have to admit!"

CMA President Dr. Chris Simpson congratulated Nowik and the association on the changes and praised the group for providing excellent representation for residents. "I know these changes will help to further cement that strong support." - Amy Thatcher, CMAJ

CMAJ 2015. DOI:10.1503/cmaj.109-5007 